\title{
RANCANG BANGUN ALAT PEMBERI PAKAN IKAN MENGGUNAKAN MIKROKONTROLER
}

\author{
Dikky Auliya Saputra ${ }^{1}$, Amarudin, S.Kom, M.Eng. ${ }^{2}$, Novia Utami, S.T., MM. ${ }^{3}$, Risky \\ Setiawan $^{4}$
}

\author{
${ }^{1}$ D3 Teknik Komputer, Universitas Teknokrat Indonesia \\ ${ }^{2,3}$ Fakultas Teknik dan Ilmu Komputer, Universitas Teknokrat Indonesia \\ ${ }^{4}$ S1 Teknik Elektro, Universitas Teknokrat Indonesia \\ Jl. ZA. Pagar Alam No.9-11, Labuhan ratu, Kec Kedaton, \\ Bandar Lampung, Lampung 35132 \\ dickysaputra454545@gmail.com, ,amarudin@teknokrat.ac.id,novia.utamiputri@gmail.com, \\ riskysetiawan231@gmail.com
}

\begin{abstract}
Abstrak
Memelihara ikan merupakan salah satu hobi dan juga dapat menjadi peluang bisnis bagi mereka yang gemar memelihara ikan hias ataupun ikan konsumsi (Elfani, 2013). Namun bagi mereka yang hanya mengisi kekosongan waktu dengan memelihara ikan tentu tidak sepenuhnya waktu diberikan untuk merawat ikan yang telah dipelihara tersebut, pemberian makan pada ikan pun tidak teratur karena sering berpergian meninggalkan ikan peliharaan ataupun malas karena bau dari pakan ikan yang tidak sedap, maka dibuatlah alat pemberi makan ikan secara otomatis.

Alat pemberi pakan ikan otomatis ini berguna untuk penjadwalan pakan ikan dimana pakan ikan dijadwalkan atau diatur oleh modul yaitu RTC (real time clock), RTC akan menjadwal 3 kali sehari yaitu pada jam 09.00, 13.00, dan 17.00 WIB. Alat ini mempunyai tempat penampung pakan, penampung sebagai tempat pakan ikan ini diberi sensor jarak. Cara kerja pada sistem ini adalah ketika program di RTC telah aktif maka dikirim ke mikrokontroler kemudian mengintruksikan pada motor servo untuk membuka katub penutup bagian bawah wadah pakan Jika pakan ikan pada wadah hampir habis maka sensor HC-SR04 akan mendeteksi dan buzzer aktif.
\end{abstract}

Kata kunci : Arduino Uno, Pakan Ikan Otomatis, Moduke RTC DS3231.

\section{Pendahuluan}

Perkembangan teknologi saat ini sudah semakin canggih dengan kemajuan yang sangat pesat dalam berbagai hal, guna memberi kemudahan manusia dalam mengerjakan pekerjaannya dan meningkatkan efisiensi produksi dalam berbagai bidang seperti budidaya, komunikasi, industri dan lain sebagainya (Nuryanto, 2012). Salah satu teknologi saat ini adalah kemampuan suatu alat yang mampu berjalan secara otomatis. Otomatisasi lebih menguntungkan bagi penggunanya dikarnakan mendapatkan kemudahan saat melakukan pekerjaan dengan hasil yang lebih efisien, ekonomis, dan praktis. Sehingga pekerjaan yang dilakukan manusia dapat lebih mudah dan lebih sedikit memakan waktu, dalam penggunaan teknologi otomatis ini dapat di implementasikan di setiap bidang kegiatan, tidak terkecuali saat memelihara ikan di dalam kolam.

Memelihara ikan merupakan salah satu hobi dan juga dapat menjadi peluang bisnis bagi mereka yang gemar memelihara ikan hias ataupun ikan konsumsi (Elfani, 2013). Namun bagi mereka yang hanya mengisi kekosongan waktu dengan memelihara ikan tentu tidak sepenuhnya waktu diberikan untuk merawat ikan yang telah dipelihara tersebut, pemberian makan pada ikan pun tidak teratur karena sering berpergian meninggalkan ikan peliharaan ataupun malas karena bau dari pakan ikan yang tidak sedap, bersumber dari pengalaman pribadi yang memelihara ikan didalam kolam yang cukup kecil dan sering ditinggal pergi, penulis berinisiatif membuat sebuah alat yang berfungsi untuk memberi makanikan secara otomatis dengan judul "Rancang Bangun Alat Pemberi Pakan Ikan Menggunakan Mikrokontroler", merupakan gagasan atau ide yang akan di implementasikan sehingga dapat digunakan pemilik untuk membantu mengatasi masalah dalam pemberian makan pada ikan hanya dengan mengisi tabung penyimpanan pakan yang nanti akan dikeluarkan secara otomatis, sehingga pemilik tidak perlu memberi makan ikan secara manual lagi dikarenakan sudah dilakukan oleh alat yang bekerja secara otomatis, dalam hal ini pemilik ikan dipermudah dalam melakukan pemeliharaan tanpa terganggu waktunya selama proses pemberian makan pada ikan yang dipelihara.

\section{Landasan Teori}

1. Arduino Uno R3

Arduino Uno R3 merupakan mikrokontroler yang berbasis chip ATmega328P, dengan 14 digital pin input / output serta 6 pin input analog, crystal $16 \mathrm{MHz}$, interkoneksi menggunakan USB, ICSP header dan tombol reset. Mikrokontroller ini biasa digunakan untuk mebuat program serta mengendalikan berbagai macam rangkian elektronika, dan memudahkan dalam membuat prototyping project. 


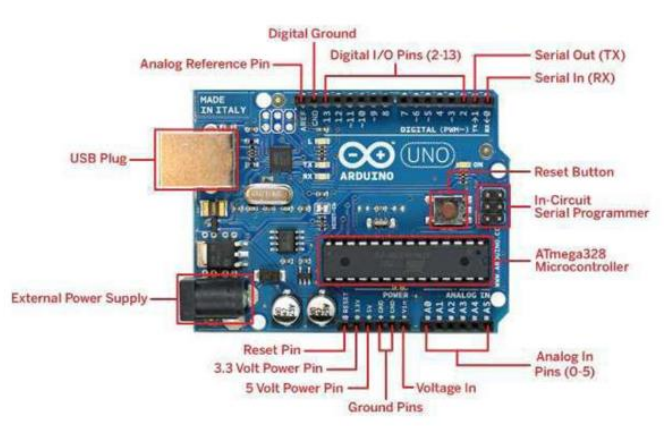

Gambar 2.1. Arduino Uno R3

\section{IDE Arduino}

Integrated Development Environment merupakan perangkat lunak yang digunakan untuk mengembangkan aplikasi mikrokontroler mulai dari menuliskan source program, kompilasi, upload hasil kompilasi dan uji coba secara terminal serial (Handayani, 2013). IDE arduino dapat dilihat pada gambar 2 .

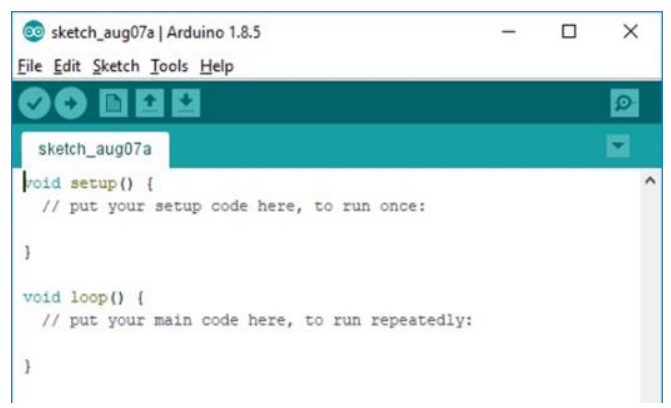

Gambar 2.2. IDE Arduino

\section{Modul Sensor Ultrasonik}

Sensor ultrasonik adalah sebuah alat yang memiliki fungsi untuk mengubah besaran fisis atau bunyi menjadi besaran listrik begitupun sebaliknya.Gelombang ultrasonik mempunyai frekuensi sebesar $20.000 \mathrm{~Hz}$. Gelombang bunyi ultrasonik tidak dapat di dengar oleh telinga manusia namun dapat mebaca jarak dari $3 \mathrm{~cm}$ sampai 3 meter, dan sudut pancaran dari 0 derajat sampai 30 derajat. Dibawah ini adalah arah pancaran gelombang ultrasonik dapat dilihat pada gambar 3 .

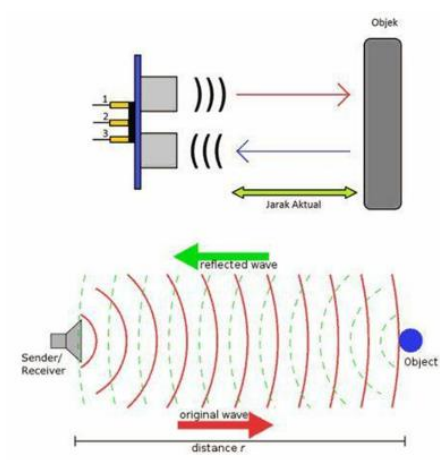

Gambar 2.3. Arah Pancaran Gelombang Ultrasonik

Jarak benda dihitung menggunakan rumus ; $\mathbf{s}=340 . \mathrm{t} / 2$. S diartikan sebagai jarak antara sensor dengan benda sedangkan $\mathbf{t}$ adalah selisih antara waktu pemancaran gelombang yang kemudian dipantulkan. Modul sensor ultrasonik ditujukan pada gambar 4 .

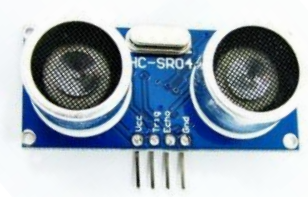

\section{Gambar 2.4. Modul Sensor Ultrasonik}

\section{LCD (Liquid Crystal Display)}

Liquid Crystal Display merupakan media yang digunakan untuk menampilkan hasil dari keluaran pada sebuah rangkaian elektronika. Fitur yang terdapat dalam LCD ini adalah:

1. 16 karakter dan 2 baris atau biasa disebut LCD $16 \times 2$

2. Memiliki 192 karakter .

3. Memiliki karakter generator yang terprogram.

4. Dapat digunakan melalui mode 4-bit dan 8-bit.

5. Dapat digunakan secara back light.

Definisi pin lcd 16x2 dapat dilihat ditabel 1 dan gambar 5 adalah device LCD.

\begin{tabular}{|l|l|}
\hline \multicolumn{2}{|l}{ Tabel 2.1. Spesifikasi LCD 16x2 } \\
\hline Pin & Diskripsi \\
\hline 1 & Ground ( - ) \\
\hline 2 & Vcc ( + ) \\
\hline 3 & Mengatur Kontras atau pencahayaan \\
\hline 4 & Register Select \\
\hline 5 & Read / Write LCD Register \\
\hline 6 & Enable \\
\hline $7-14$ & Data I/O (input output) \\
\hline 15 & VCC ( + ) LED \\
\hline 16 & Ground ( - ) LED \\
\hline
\end{tabular}

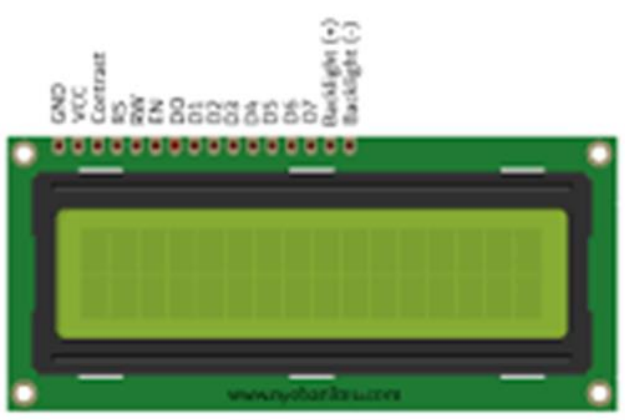

Gambar 2.5. LCD (Liquid Crystal Display) 16x2 


\section{I2C/TWI LCD 1602}

Merupakan modul yang dipakai untuk mengurangi penggunaan kaki di LCD 1602. Modul ini memiliki 4 Pin yang akan dihubungkan ke Arduino (Wilmshurst, 2009).

1. GND : dihubungkan ke GND Arduino

2. VCC : dihubungkan ke $5 \mathrm{~V}$ Arduino

3. SDA : Merupaakan I2C data dan dihubungkan ke pin analog pada arduino

4. SCL : Merupakan I2C clock dan dihubungkan ke pin analog pada arduino.

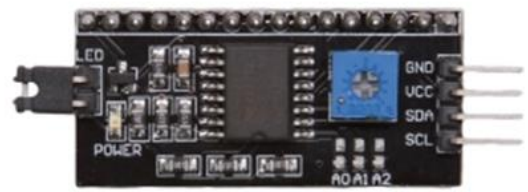

Gambar 2.6. Modul I2C LCD 1602

\section{Real Time Clock (RTC) DS3231}

Modul RTC DS3231 adalah jenis modul yang berfungsi sebagai Real Time Clock atau pewaktuan digital serta pengukur suhu. I2C atau two wire (SDA dan SCL) digunakan sebagai antar muka pada modul ini.

Terdapat pula EEPROM AT24C32 yang digunakan untuk menyimpan data, ini adalah pilihan terbaik untuk aplikasi yang memerlukan untuk fitur data logging, dengan presisi waktu yang lebih tinggi (Abdul Kadir, 2016)

Berikut fungsi dari pin yang terdapat pada RTC DS3231.

1. SCL

Berfungsi sebagai clock pada inputan ke I2C dan untuk mensinkronkan pergerakan data dalam serial interface.

2. SDA

Berfungsi sebagai I/O pada I2C.

3. GND atau Ground

Berfungsi untuk mengurangi noise yang disebabkan oleh asupan daya yang kurang optimal, dan kualitas komponen yang buruk.

4. VCC

Berfungsi sebagai sumber tegangan utama. Agar dapat mengakses dan membaca data dengan baik.

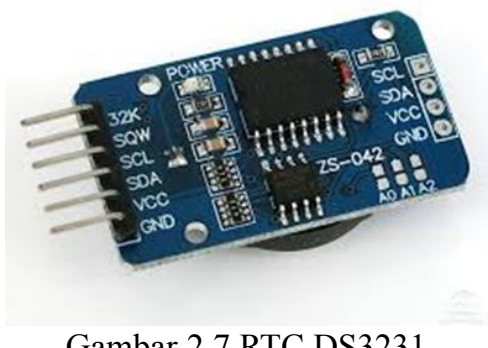

\section{Keypad 3x4}

Keypad matriks yang disusun dalam empat baris dan tiga kolom.

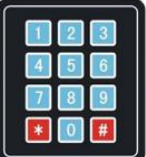

Gambar 2.8. Keypad 3x4

Apabila saklar 1 ditekan maka baris 1 dan kolom 1 akan terhubung. Apabila saklar 2 ditekan maka baris 1 dan kolom 2 akan terhubung, dan seterusnya (Abdul Kadir, 2016). prisipnya hampir sama dengan skalar berikut gambarnya

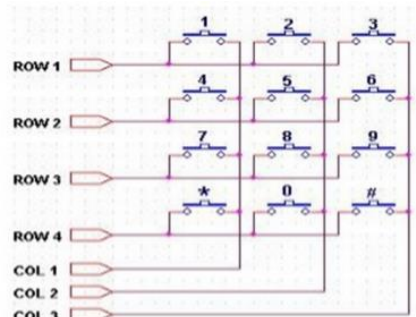

Gambar 2.9 Interface Keypad 3x4

\section{Motor Servo (Servo Motor)}

Motor servo adalah motor yang dapat bekerja searah jarum jam cloackwise $(\mathrm{CW})$ dan berlawanan arah jarum jam counter cloackwise (CCW). Arah serta sudut gerak rotornya dapat dikendalikan melalui pengaturan duty cycle sinyal PWM pada bagian pin kontrolnya. Motor servo juga memiliki rangkaian kontrol elektronik dan internal gear yang digunakan untuk mengendalikan kecepatan gerak dan sudutnya.

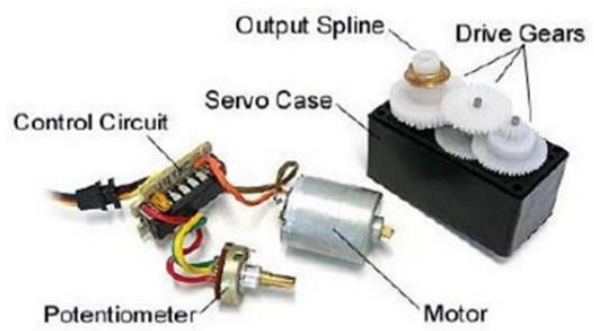

Gambar 2.10. Sistem mekanik motor servo

\section{Buzzer}

Buzzer digunakan untuk mengubah getaran listrik menjadi getaran suara. Prinsip kerjanya hampir sama dengan loud speaker, yang terdiri dari kumparan yang dipasang pada bagian diafragma dan kemudian dialiri arus listrik sehingga bersifat elektromagnetis, kumparan terssebut akan tertarik ke arah dalam atau keluar, tergantung arah arus dan polaritasnya. Buzzer biasanya dijadikan sebagai indikator sebuah proses telah selesai atau menjadi indikator abnormal pada sebuah alat . 


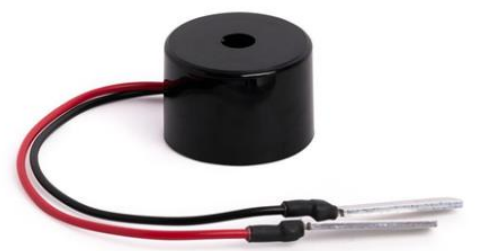

Gambar 2.11. Buzzer

\section{Rancangan dan Pengujian}

\section{Blog Diagram}

Perancangan alat dimaksudkan untuk mempermudah dalam pengerjaan. Dalam melakukan pengerjaan terlebih dahulu membuat suatu blok diagram sistem dari alat yang akan dikerjakan. Dengan adanya blok diagram ini dapat mempermudah menjelaskan prinsip kerja alat. Adapun blok diagram sistem ini dapat dilihat pada gambar berikut:

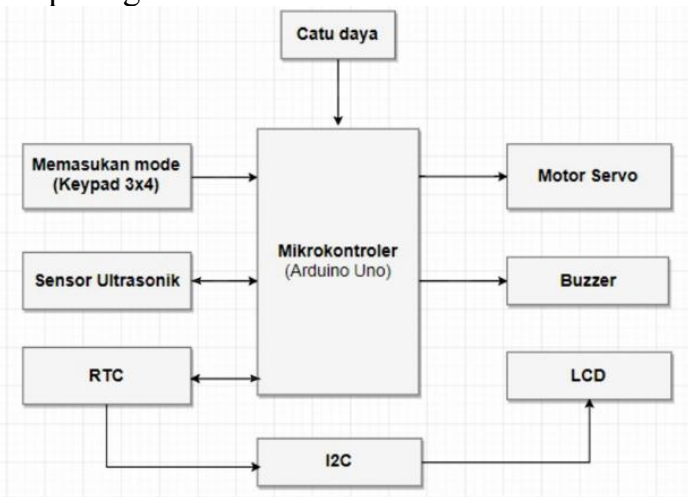

Gambar 3.1. Diagram Blok Alat

Dari blok diagram dapat dijelaskan fungsi masing-masing blok sistem, sebagai berikut:

1 Catu Daya

Berfungsi sebagai sumber listrik pada alat ini, karena pada setiap rangkaian membutuhkan supply dalam bentuk tegangan dc.

2 RTC (real time clock)

Berfungsi sebagai input, dimana modul ini bekerja sebagai pewaktu/penjadwal pakan ikan pada sistem.

3 HCSR-04/Sensor jarak

Sensor ini berfungsi sebagai pendeteksi jumlah pakan pada bak penampung pakan ikan.

4 Arduino Uno

Mikrokontroler arduino uno sebagai kontroler dari keseluruhan sistem yang akan mengatur kinerja dari sistem pengatur alat.

5 Motor Servo

Berfungsi sebagai pembuka dan penutup mekanik buka tutup pada penampung pakan.

6 Buzzer

Digunakan sebagai indikator peringatan bahwa pakan ikan pada penampungan hampir habis, jika pakan hampir habis maka buzzer akan aktif mengeluarkan bunyi dan sebaliknya.
$7 \quad$ LCD (liquid cristal display)

Digunakan sebagai penampil waktu dan mode otomatis yang akan dipilih.

$8 \quad$ Keypad $3 \times 4$

Berfungsi sebagai tombol untuk menentukan tipe mode yang dipilih pada tampilan di lcd.

$9 \quad$ I2C (inter integreted circuit)

Berfungsi sebagai modul yang digunakan untuk mengubah jalur kendali lcd dari paralel ke serial yang bertujuan untuk menghemat pin pada kontroler yang terhubung ke lcd.

\section{Pengujian}

Setelah melakukan pembuatan sistem pengontrolan waktu pemberian pakan ikan menggunakan RTC (real time clock). Pada bab ini penulis akan membahas pengujian rangkaian alat. Pengujian alat ini bertujuan untuk mengetahui apakah alat tersebut telah sesuai dengan yang direncanakan sebelumnya. Pada pengujian alat ini, penulis akan menguji masing-masing komponen yang digunakan pada alat. Pengujian yang akan dilakukan pada alat ini adalah sebagai berikut:

1. Pengujian Catu Daya.

2. Pengujian Mikrokontroler.

3. Pengujian Motor Servo.

4. Pengujian Sensor Ultrasonik.

5. Pengujian LCD.

6. Pengujian Real Time Clock.

7. Pengujian Keypad.

\section{Pengujian Catu Daya}

Pengujian ini dilakukan dengan tujuan apakah semua komponen yang terhubung dapat menerima sumber tegangan secara baik dan menghindari perkabelan yang buruk atau terputus sehingga tidak ada salah satu komponen yang tidak menyala akibat tidak terpasok sumber tegangannya. Karna semua komponen mengambil daya dari mikrokontroler maka pengujian catudaya cukup dengan menghubungkan mikrokontroler pada sumber tegangan seperti adaptor, powerbank, ataupun leptop. Disini penulis menggunakan leptop

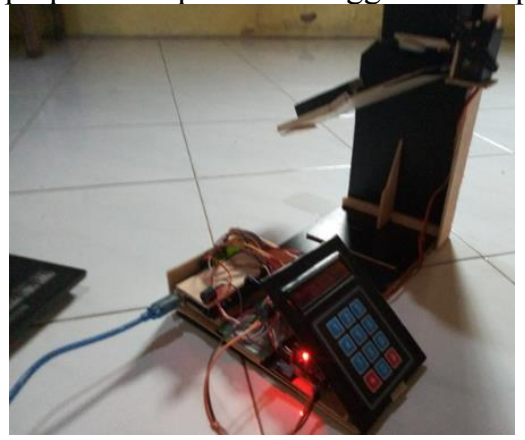

Gambar 3.2 Pengujian Catu Daya Pada Alat

Dapat dilihat bahwa sistem hidup, berarti bahwa catu daya berfungsi pada alat.

\section{Pengujian Mikrokontroler}

Pengujian selanjutnya dilakukan pada mikrokontroler 
Arduino Uno yang mana bagian ini merupakan pusat pengolahan data pada sistem penjadwalan ini. Pengujian ini dilakukan dengan memprogram mikrokontroler arduino dan mengukur pin output menggunakan multimeter.

Langkah - langkah untuk pengujian Arduino Uno

1. Menyediakan alat dan bahan

a. Arduino Uno

b. Multimeter

c. Kabel downloader

d. Software arduino

e. Laptop

2. Cara Pengujian

a. membuat program menggunakan software pada Arduino Uno, beri logika 1 (HIGH) pada PIN 1 dan pada PIN 2 beri logika 0 (LOW) seperti program dibawah ini:

void setup ()\{

pinMode (1,OUTPUT); pinMode (2,OUTPUT);

\}

void loop () \{

digitalWrite $(1, \mathrm{HIGH})$;

$\operatorname{delay}(1000)$;

digitalWrite(2,LOW);

delay(1000);

\}

setelah program selesai dibuat maka upload program tersebut kedalam mikrokontroler arduino Uno menggunakan kabel USB.

b. Mengkalibrasi multi meter dan letakan selector pada Vdc dengan batas skala 10Vdc.

c. Memberikan suplay 5 volt dc pada mikrokontroler, melakukan pengukuran pada PIN 1 dan PIN 2 arduino.

3. Hasil Pengujian

Setelah diukur dengan multi meter, maka didapat data seperti tabel berikut:

Tabel 3.1 Hasil Pengujian Output Mikrokontroler

\begin{tabular}{|c|c|c|}
\hline \multicolumn{2}{|c}{ Arduino Uno } \\
Titik & Logika & Tegangan \\
Pengukuran & Program & Terbaca \\
\hline PIN 1 & 1 & $5 \mathrm{v}$ \\
\hline PIN 2 & 0 & 0 \\
\hline
\end{tabular}

Setelah mengupload program kedalam arduino maka diukurlah tegangan pada pin 1 dan pin 2 jika dilihat pada tabel 4.1, pin 1 yang diberi logika $\mathrm{HIGH}$ memiliki tegangan output sebesar $5 \mathrm{Vdc}$ sedangkan pin 2 yang diberi logika LOW memiliki tegangan output $0 \mathrm{Vdc}$.

\section{Pengujian Motor Servo}

Pengujian yang dilakukan berikutnya adalah pengujian Motor Servo, karena sebagai penggerak mekanik agar pakan ikan dapat keluar dari wadah penampungan maka motor servo harus dilakukan pengujian agar pakan ikan dapat keluar, pengujian dilakukan dengan cara mengaktifkan penjadwalan dengan waktu yang bukan sebenarnya dengan selisih setiap waktu 5 menit pada program yang di download, hasil dari pengujian bisa dilihat pada tabel berikut :

Tabel 3.2 Hasil Pengujian Motor Servo

\begin{tabular}{|r|c|c|c|}
\hline No & Jam Penjadwalan & Jam makan & Motor Servo \\
\hline 1 & 09.10 & Pagi & Terbuka \\
\hline 2 & 09.15 & Siang & Terbuka \\
\hline 3 & 09.20 & Sore & Terbuka \\
\hline 4 & 09.25 & Pagi & Terbuka \\
\hline 5 & 09.30 & Siang & Terbuka \\
\hline 6 & 09.35 & Sore & Terbuka \\
\hline
\end{tabular}

Dari hasil pengujian pada tabel 4.2 diambil contoh 6 kali penjadwalan dengan selisih tiap waktunya adalah 5 menit dan mensimulasikan jam makan pagi, siang, dan sore pada ikan. Motor Servo pun berfungsi dengan baik dan sesuai dengan apa yang diharapkan pada saat sistem bekerja. Gambar 3.3 adalah ketika motor servo sedang terbuka

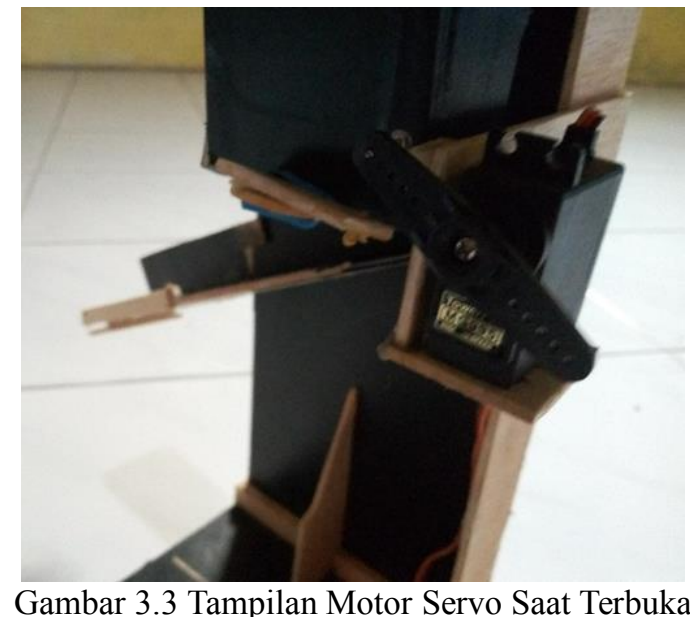

\section{Pengujian Sensor Ultrasonik}

Pengujian Sensor Ultrasonik dimaksudkan untuk mengetahui seberapa tepat dan akurat sensor HC-SR04 ini dalam menentukan jarak pakan ikan yang terdapat didalam penampung, sehingga mampu menilai tingkat ketepatan sistem saat membaca jarak dan mengirimkan nilai pembacaannya ke mikrokontroler, cara yang dilakukan adalah melakukan pengukuran sensor jarak dengan penggaris dan penghalang dengan jarak $20 \mathrm{~cm}$ saja. Hasil pengukuran dapat diperlihatkan pada tabel 3.3 
Tabel 3.3 Hasil Pengujian Sensor Ultrasonik

\begin{tabular}{|c|c|c|}
\hline No & Data Sensor $(\mathrm{cm})$ & Jarak Sebenarnya $(\mathrm{cm})$ \\
\hline 1 & 2 & 2 \\
\hline 2 & 2 & 3 \\
\hline 3 & 3 & 3 \\
\hline 4 & 3 & 4 \\
\hline 5 & 4 & 4 \\
\hline 6 & 4 & 5 \\
\hline 7 & 5 & 5 \\
\hline 8 & 5 & 6 \\
\hline 9 & 6 & 6 \\
\hline 10 & 6 & 7 \\
\hline
\end{tabular}

Dari data yang telah diuji maka dapat diketahui bahwa selisih dari sensor jarak dengan jarak sebenarnya tidak terpaut jauh atau masih bisa dikatakan dalam toleransi kesalahan, sehingga sensor jarak berfungsi dengan baik pada sistem ini.

\section{Pengujian LCD (Liquid Crystal Display)}

Pengujian pada LCD dimaksudkan agar dapat mengetahui bahwa LCD mampu menampilkan informasi dengan baik dan sesuai dengan apa yang diharapkan pada sistem saat menginputkan jadwal pemberian pakan pada ikan. Pengujian dilakukan dengan cara menampilkan semua yang berhubungan dengan tampilan layar pada LCD berikut gambar untuk memperlihatkan hasil pengujian LCD pada saat digunakan.

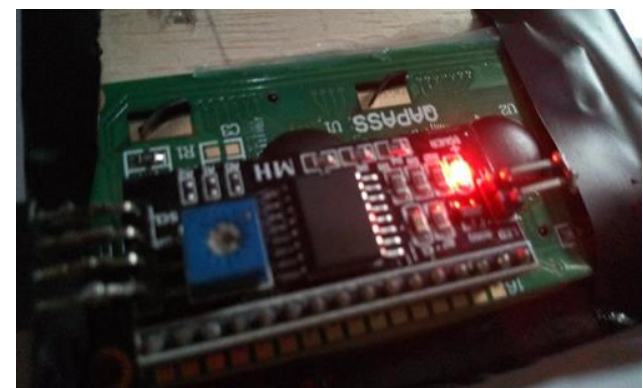

Gambar 3.4 Tampilan I2C Menyala Saat Mendapat Tegangan

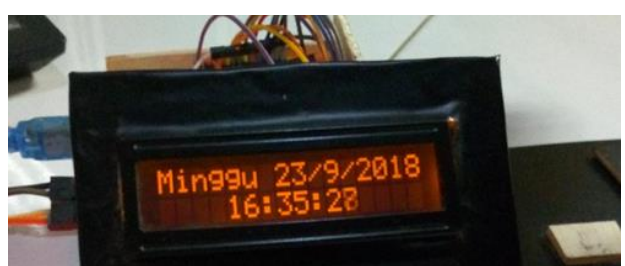

Gambar 3.5 LCD Menampilkan Waktu Saat Menyala

Gambar 3.4 adalah notif led pada i2c saat lcd menerima tegangan dari mikrokontroler melalui RTC sedangkan gambar 3.5 adalah tampilan pada layar LCD ketika sistem pada alat dalam keadaan standby.

\section{Pengujian Real Time Clock}

Pengujian RTC bertujuan untuk mngetahui apakah RTC mampu menjadi pewaktu seperti jam digital (handphone). Pada pengujian kali ini dilakukan perbandingan jam makan pagi, jam makan siang, dan jam makan sore yang di setting pada program untuk jam RTC dengan jam digital (handphone). Cara pengujian dilakukan dengan mengganti waktu pemberian pakan ikan, dengan selisih 5 menit disetiap waktunya, hasil pengujian dapat dilihat pada table 3.4

Tabel 4.4 Hasil Pengamatan Jam RTC Dan Jam Digital (handphone)

\begin{tabular}{|c|c|c|c|c|}
\hline No & $\begin{array}{c}\text { Jam } \\
\text { Handphone }\end{array}$ & $\begin{array}{c}\text { Jam Settingan } \\
\text { RTC }\end{array}$ & $\begin{array}{c}\text { Simulasi Jam } \\
\text { Makan }\end{array}$ & Eror \\
\hline & & & & \\
\hline 2 & 07.55 & 07.54 & Siang & 1 menit \\
\hline 3 & 08.00 & 07.59 & Sore & 1 menit \\
\hline 4 & 08.05 & 08.04 & Pagi & 1 menit \\
\hline 5 & 08.10 & 08.09 & Siang & 1 menit \\
\hline 6 & 08.15 & 08.14 & Sore & 1 menit \\
\hline 7 & 08.20 & 08.19 & Pagi & 1 menit \\
\hline 8 & 12.02 & 12.01 & Siang & 1 menit \\
\hline 9 & 12.07 & 12.06 & Sore & 1 menit \\
\hline 10 & 12.12 & 12.11 & Pagi & 1 menit \\
\hline 11 & 12.17 & 12.16 & Siang & 1 menit \\
\hline 12 & 12.22 & 12.21 & Sore & 1 menit \\
\hline 13 & 12.27 & 12.26 & Pagi & 1 menit \\
\hline 14 & 14.06 & 14.05 & Siang & 1 menit \\
\hline 15 & 14.11 & 14.10 & Sore & 1 menit \\
\hline & & & & \\
\hline
\end{tabular}

Dari tabel 4.4 diatas dapat dilihat bahwa pengujian alat yang dilakukan sebanyak $15 \mathrm{kali}$, pada percobaan jam RTC dengan jam digital (handphone) memiliki perbedaan waktu selama 1 menit dengan kata lain jam RTC lebih lambat 1 menit dibanding dengan jam digital (handphone). Itu terjadi karena saat mendownload program RTC membutuhkan waktu untuk proses sampai pada mikrokontroler untuk menginisialisasikan pin dan menyelesaikan prosesnya. Gambar dari RTC yang menyala saat diberikan tegangan adalah seperti pada gambar 3.6 berikut,

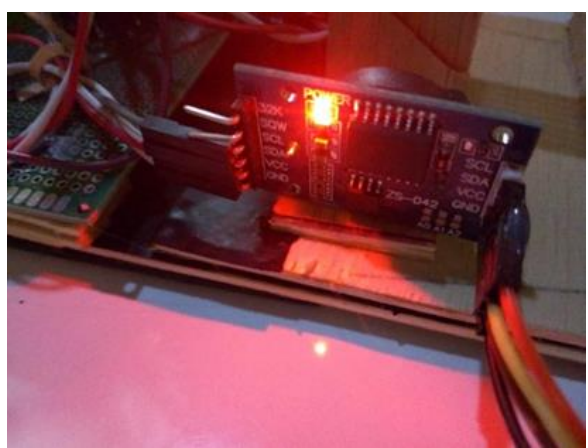

Gambar 3.6 Tampilan RTC Menyala Saat Mendapat Tegangan

\section{Pengujian Keypad}


Pengujian pada Keypad dimaksudkan agar dapat mengetahui bahwa Keypad mampu memasukan mode dengan baik dan sesuai dengan apa yang diharapkan pada sistem saat menginputkan jadwal pemberian pakan pada ikan. Pengujian dilakukan dengan cara menampilkan semua yang berhubungan dengan tampilan layar pada LCD yang menampilkan hasil dari inputan dari Keypad berikut gambar untuk memperlihatkan hasil pengujian Keypad pada saat digunakan.

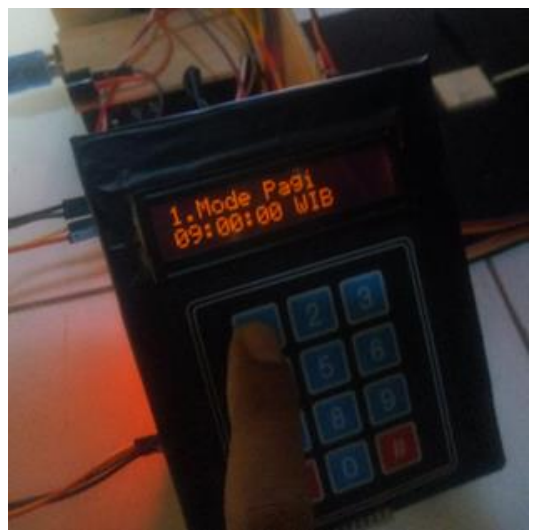

Gambar 3.7 LCD Menampilkan hasil Input Tombol 1 Dari Keypad

Saat menekan tombol 1 pada keypad berarti kita mengaktifkan mode pagi hari dimana sistem akan memberi pakan ikan pada jam 9 pagi sesuai dengan apa yang ditampilkan pada layar lcd. Seperti pada gambar 3.7 diatas.

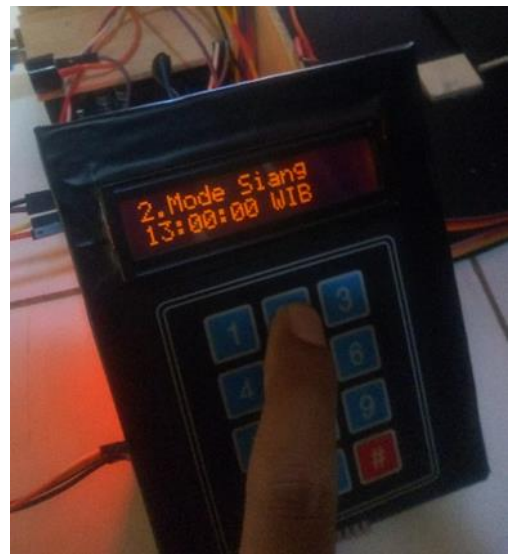

Gambar 3.8 LCD Menampilkan hasil Input Tombol 2 Dari Keypad

Apabila menekan tombol 2 pada keypad berarti kita mengaktifkan mode siang hari dimana sistem akan memberi pakan ikan pada jam 1 siang sesuai dengan apa yang ditampilkan pada layar lcd. Seperti gambar 3.8

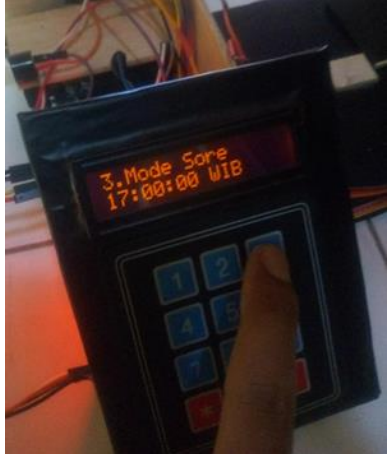

Gambar 3.9 LCD Menampilkan hasil Input Tombol 3 Dari Keypad

Dan apabila menekan tombol 3 pada keypad berarti kita mengaktifkan mode sore hari dimana sistem akan memberi pakan ikan pada jam 5 sore sesuai dengan apa yang ditampilkan pada layar lcd. Seperti gambar 3.9

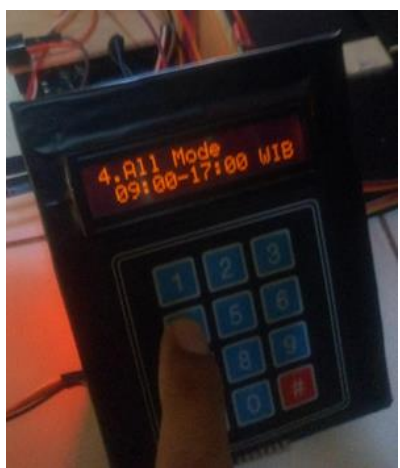

Gambar 3.10 LCD Menampilkan hasil Input Tombol 4 Dari Keypad

Apabila menekan tombol 4 pada keypad berarti kita mengaktifkan Allmode yang berarti sistem akan menjadwalkan semua waktu sekaligus, jadi sistem akan memberi pakan ikan disetiap jam 9 pagi, 1 siang, dan 5 sore sekaligus sesuai dengan apa yang ditampilkan pada layar lcd. Seperti gambar 3.10

\section{Kesimpulan}

Dari hasil pengujian yang telah dilakukan pada alat maka dapat ditarik kesimpulan bahwa :

1. Komponen yang digunakan dalam pembuatan alat berupa Arduino Uno, Sensor Ultrasonik HC-SR04, RTC (Real Time Clock), LCD (Liquid Crystal Display) 16x2, Keypad, Buzzer, Motor Servo, dan Triplek yang digunakan sebagai kerangka dan wadah penampung pakan dapat berfungsi dengan baik.

2. Pembuatan Alat Pemberi Pakan Ikan Menggunakan Mikrokontroler ini menggabungkan komponen yang dikontrol mikrokontroler arduino dengan RTC (Real Time Clock) sebagai penjadwalan waktu sehingga dapat bekerja untuk mengeluarkan pakan didalam wadah yang terbuat dari triplek. 
3. RTC (Real Time Clock) dapat berfungsi dengan baik sebagai penjadwalan pada alat pemberi pakan ikan ini sesuai dengan waktu sebenarnya.

4. Sensor Jarak Ultrasonik sebagai pembaca nilai jarak pada penampungan pakan ikan memiliki tingkat eror yang cukup rendah sehingga dapat berfungsi dengan baik.

5. Alat ini bekerja untuk mmemberi pakan ikan terjadwal di jam 09.00 WIB, 13.00 WIB, dan 17.00 WIB.

6. Ketika sensor jarak membaca nilai jarak pakan ikan pada wadah lebih dari atau sama dengan 18 maka buzzer otomatis aktif.

7. Waktu dalam pengujian pemberian pakan ikan dilakukan dengan selisih waktu 5 menit dari jadwal sebenarnya yang berselisih 3 jam.

8. Alat ini masih sebatas perancangan dan prototipe.

\section{Saran}

Berdasarkan percobaan yang telah dilakukan dan hasil yang telah dicapai, penulis menyadari bahwa masih banyak kekurangan pada sistem alat ini, maka terdapat beberapa saran agar kedepannya alat ini dapat bekerja dengan lebih baik dan lebih optimal lagi, saran yang dapat diberikan diantaranya :

1. Agar dapat memberikan sistem pengontrolan suhu dan kekeruhan pada air kolam sehingga dapat mengganti dengan air yang lebih baik.

2. Ditambahkannya pengontrolan jarak jauh via sms, IoT, atau lain sebagainya yang dapat lebih mempermudah pengontrolannya.

3. Dapat digunakan di kolam yang lebih besar.

4. Membesarkan wadah penampung pakan sehingga daya tampung pakan dapat lebih banyak dan tidak sering melakukan pengisian ulang pakan ikan.

5. Alat tidak hanya bekerja sehari tetapi tetap dapat bekerja dengan optimal meski ditinggal lebih dari seminggu atau lebih.

\section{Daftar Pustaka}

[1] [AOTA] "American Occupational Therapy Association”. 2014. Backpack Strategies for Parents and Students. http://www.aota.org

[2] [APTA] “American Physical Therapy Association". 2013. Journal The American Physical Therapy Association, http://www.apta.org

[3] Anonym. 2015. "Loadcell Teori/Loadcell Handbook". https://loadcellteori.wordpress.com/.

[4] Bangun, Suprapto. 2011. "Teori Kelistrikan Loadcell”. Telkomnika, Vol. 7,No. 2, 103 - 108; ISSN 1693-6930

[5] Jurnal Elkomika. Wahyudi, Abdur Rahman, Muhammad Nawawi. 2017. "Perbandingan Nilai Ukur Sensor Loadcell Pada Alat Penyortir Buah Otomatis Terhadap Timbangan Manual". https://eprints.polsri.ac.id

[6] Jurnal Kesehatan Masyarakat. 2017. http://ejournal3.undip.ac.id/index.php/jkm

[7] Jurnal Legiran. "Berat Tas Punggung dan Prevalensi Nyeri Punggung Pada Siswa Sekolah Dasar". https://core.ac.uk

[8] Jurnal Muhammad Syiradjudin, Slamet Winardi. 2016. "Pembuatan Prototype dan Ransel Anak Sekolah Dengan Mikrokontroler Arduino Uno. https://sistemkomputer.narotama.ac.id

[9] Kadir, Abdul. 2013. "Panduan Praktis Mempelajari Aplikasi Mikrokontroler dan Pemrogramannya menggunakan Arduino". Yogyakarta : Andi.

[10] Katarzyna, et al,. 2015. "Influence of the Weight of a School Backpack on Spinal Curvature in the Sagittal Plane of Seven-Year-Old Children". http://www.ncbi.nlm.nih.gov/pubmed/26413545.G. Smith, "Paper Title" (to be published). 